\title{
Normal values of inner and outer intercanthal distances in a student population in southeast Nigeria
}

\author{
O. A. EGWU ${ }^{1 *}$, E. O. EWUNONU ${ }^{1}$, A. N. ETEUDO ${ }^{1}$, K. N. OVUOBA ${ }^{1}$, C. O. NJOKU ${ }^{1}$ and \\ A. C. UGWU ${ }^{2}$ \\ ${ }^{1}$ Department of Anatomy, Ebonyi State University, Abakaliki, Nigeria. \\ ${ }^{2}$ Department of Medical Radiography and Radiological Sciences, Nnamdi Azikiwe University, Nnewi Campus, \\ Anambra State, Nigeria. \\ *Corresponding author, E-mail: egwuoc@yahoo.com
}

\begin{abstract}
Normal values of inner and outer intercanthal distances in a student population in Nigeria were studied. A total of 460 students (264 males and 196 females) with mean age of $23.27 \pm 3.48$ years for males and $21.37 \pm 2.82$ years for females volunteered to be subjects in this study. The inner intercanthal distance (IICD) and outer intercanthal distance (OICD) were measured between the medial and lateral ends of the palpabral fissures respectively using a metric ruler. Other measurements taken were height, weight, fronto-occipital distance (FOD). The mean IICD for males and females were $43.90 \pm 4.11 \mathrm{~mm}$ and $41.77 \pm 3.37 \mathrm{~mm}$ respectively. The canthal index (CI) showed $37.10 \pm 2.93$ for males and $36.41 \pm 2.69$ for females. Non-parametric t-test evinced no significant $(\mathrm{P}>0.05)$ difference between the sexes for $\mathrm{CI}(\mathrm{P}=0.841)$. Pearsons correlation coefficient indicated positive relationship between IICD, OICD, CI, FOD and Body surface area (BSA). IICD and OICD correlated with height while OICD alone correlated with Body mass index (BMI). A multiple regression equation was developed for $\mathrm{CI}$ as dependent variable and FOD, Age and height as independent variables. This study will provide a databank for craniofacial surgeons and ophthalmologists and help in the evaluation of deformities, post-traumatic telecanthus and hypertelorism in our population.
\end{abstract}

(c) 2008 International Formulae Group. All rights reserved.

Keywords: Inner intercanthal distance, Outer intercanthal distance, Canthal index, Students, Southeast Nigeria.

\section{INTRODUCTION}

Physical anthropometry has been of immense importance in medicine and health sciences. Measurements from different studies have been used to determine age, sex, race and in some cases ethnicity. They have also been used to detect anomalies of development. Such measurements are at times specific for age, sex, race and ethnic groups and have been used to infer genetic and possible environmental factors that contribute to such specificity.

The intercanthal distance of humans is an anthropometric parameter that can be used to detect congenital malformation, hypertelorism, traumatic telecanthism and naso-orbitoethmoid injury. The canthi are angles or ends of palpabral fissure, which are elliptical spaces between the upper and lower eyelids. The lateral canthus is more acute than the medial, being closely apposed to the eyeball while the medial canthus is prolonged towards the nose about $6 \mathrm{~mm}$ from the eyeball (Williams et al., 1995).

The inner and outer intercanthal distances (IICD and OICD) are the distances between the medial and lateral canthi respectively. Bruce and Timothy (1992) stated that the normal IICD is about $34 \pm 4 \mathrm{~mm}$ and varies considerably among races and certain ethnic groups. Everekliogu et al. (2002) reported that IICD and OICD varied for different age groups and that OICD was significantly wider in males than in females. Murphy and Laskin (1990) recorded an average IICD of $33.9 \pm 3.0 \mathrm{~mm}$ for a black 
population in the USA and suggested that it was similar to findings in whites and mixed populations. In an Indian population, the normal values of IICD and OICD were observed to be lower than other races studied (Gupta et al., 2003) and Hong Kong Chinese adults were reported to have higher IICD value than Caucasians and other populations in Mainland China (Quant and Woo, 1992).

Numerous studies have shown that there are many pathological, congenital and trauma-induced conditions that affect the canthal index including its IICD and OICD components (Zhang et al., 2000; Freihofer, 1980; Everelioglu et al., 2000). These conditions like hypertelorism, posttraumatic telecanthus, naso-orbitoethmoidal injuries, cleft palate either increase or decrease the IICD and OICD as the case may be. Apart from pathology, trauma and congenital malformations, environmental and genetic factors play a role of varying degree in determination of $\mathrm{CI}$ and its components. Therefore, the need for intraspecific assessment of canthal parameters in our environment is underscored bearing in mind the indispensable role of environment in prepubertal and post-pubertal growth and development.

From the aforementioned, it is pertinent to develop a databank of normograms for IICD, OICD and Canthal Index (CI) for our immediate environment and also following that Internet search engines could not reveal such study for our immediate environment, this study will serve as a guidepost for surgeons in the detection of anomalies and trauma-induced craniofacial changes. The study also correlates IICD, OICD, and CI with other anthropometric variables like body surface area (BSA), weight, height, body mass index (BMI) and Fronto-occipital distance (FOD).

\section{MATERIALS AND METHODS}

Four hundred and sixty (460) students (264 males and 196 females) of Ebonyi State University, Abakaliki, Nigeria, who were without any history of craniofacial trauma or congenital malformation of the head and neck volunteered for this study. This followed the approval by the Ethics/research Committee of the College of Health Sciences, Ebonyi State University, Abakaliki, Nigeria.

\section{Measurements}

The IICD and OICD were measured using a transparent metric ruler calibrated in millimeters. The FOD (Glabella to Inion) and height were measured using a measuring tape. One person took two measurements for each parameter and the highest value taken. This was to avoid interobserver variability. Weights were taken with a weighing balance and the BMI, BSA and CI were calculated using the following formulae:

BMI $=$ Weight $/(\text { Height })^{2}$;

$\mathrm{BSA}=\mathrm{W}^{0.425} \mathrm{X} \mathrm{H}^{0.725} \mathrm{X} 0.007184$

where $\mathrm{W}=$ weight and $\mathrm{H}=$ height

and $\mathrm{CI}=\mathrm{IICD} / \mathrm{OICD} \mathrm{X} 100$.

\section{Statistical analysis}

Non-parametric t-test was used to compare means of both sexes, while Pearsons correlation coefficient was used to establish statistical relationships.

\section{RESULTS}

The results obtained are shown in table 1. The table shows the mean values of all parameters measured for both sexes. The average age of the study population was $22.46 \pm 3.34$ years. The average IICD, OICD and CI were $42.99 \pm 0.39,116.81 \pm 0.61$ and $36.81 \pm 2.84 \mathrm{~mm}$, respectively. The mean values for BSA, BMI and FOD include $0.06176340 \pm 0.005226939,22.19 \pm 2.56$, and $38.78 \pm 1.09 \mathrm{~cm}$, respectively.

\section{Statistical analysis}

Non-parametric t-test showed that there was no significant $(\mathrm{P}>0.05)$ difference between the sexes for CI. Also, Pearsons correlation coefficient showed that IICD, OICD and CI were positively related to FOD ( $\mathrm{r}=0.283 ; 0.233$ and 0.171 , respectively). They also correlated with BSA ( $r=0.324$; 0.457 and 0.481 , respectively). IICD and OICD correlated with height $(\mathrm{r}=0.287$ and 0.371 , respectively) while OICD correlated with BMI $(r=0.205)$. A simple regression equation was developed for IICD as follows:

$\mathrm{IICD}=1.957+1.378($ Height $)$ 
Table 1: Mean parameters of the intercanthal distance in a student population in Nigeria.

\begin{tabular}{lcccc}
\hline Parameters & Males & Females & Range & Total mean \\
\hline Age $($ year) & $23.27 \pm 3.48$ & $21.37 \pm 2.82$ & $17-28$ & $22.46 \pm 3.34$ \\
IICD $(\mathrm{mm})$ & $43.90 \pm 0.41$ & $41.77 \pm 0.34$ & $28-46$ & $42.99 \pm 0.39$ \\
OICD $(\mathrm{mm})$ & $118.34 \pm 0.66$ & $114.76 \pm 0.34$ & $112-121$ & $116.81 \pm 0.61$ \\
CI & $37.1 \pm 2.93$ & $36.41 \pm 2.69$ & $29.30-38.42$ & $36.81 \pm 2.84$ \\
FOD $(\mathrm{cm})$ & $38.84 \pm 2.35$ & $38.78 \pm 1.09$ & $36.50-39.25$ & $38.80 \pm 1.00$ \\
Height $(\mathrm{m})$ & $1.74 \pm 0.071$ & $1.64 \pm 0.06$ & $1.58-1.79$ & $1.66 \pm 0.08$ \\
Weight $(\mathrm{kg})$ & $66.35 \pm 8.39$ & $61.16 \pm 9.0$ & $53-81$ & $65.45 \pm 7.65$ \\
\hline
\end{tabular}

IICD = Inner Intercanthal Distance; OICD = Outer Intercanthal Distances; CI = Canthal Index; FOD = Fronto-Occipital Distance.

Based on results of measurements, a simple regression equation was developed for OICD as the dependent variable and height as the independent variable, thus:

$$
\mathrm{OICD}=6.966+2.775(\text { Height })
$$

A multiple regression equation was developed for CI (dependent Variable) and the height, FOD and Age as independent variables, thus:

$\mathbf{C I}=0.238+0.01918$ (Height) +0.002417 (FOD) +0.0001447 (Age)

\section{DISCUSSION}

The results of the present study show that the IICD of the sampled population can be classified as being on the high side when compared to other studies. Bruce and Timothy (1992) reported 34 $\pm 4 \mathrm{~mm}$; Murphy and Laskin (1990) reported 33.9 $\pm 3.0 \mathrm{~mm}$; Ngeow and Akan (2005) reported 33.0 $\pm 2.6 \mathrm{~mm}$ for Malaysians in Kuala Lumpur; and Gupta et al. (2003) reported a range of 20-36 $\mathrm{mm}$ for an Indian population. These differences that are quite significant could be attributed to racial and ethnic differences caused by environmental and genetic factors that control pre-pubertal and post-pubertal development of the upper third of the face.

The correlations observed between IICD, OICD and height indicate that the genetic and environmental factors that control the individual's height equally control development of the upper face. Hence, the simple regression equations developed for determination of both canthal parameters is not disjunctive and could serve as model equations that will assist optometrists and ophthalmologists in the design of facio-orbital sight, correcting components with an optimum fit. Also, the multiple regression equation relating the canthal index with height, age and FOD could also be helpful in the design of facio-orbital components with optimum fit for users and patients within our environment since the canthal parameters correlated with FOD and since age is a factor relatively and intimately associated with growth. All the developed formulae could also be very useful in the surgical correction of hypertelorism, traumatic telecanthus and other nasoorbitoethmoidal injuries because using an individual's height, age and FOD, the canthal index (CI), OICD and IICD could be deduced especially for this particular student age group in the southeast Nigeria. Therefore, craniofacial surgeons should consider revalidation of the developed equations for use and even biomedical engineers could ascertain their importance in the design of models fit for prosthetics.

This study has tried to consider the intraspecific attributes of anthropometrical variables. Its novelty draws from the fact that all Internet search engines employed did not reveal that such study has been carried out in our immediate environment. Further studies involving age-related changes of IICD and OICD and deduction of predictive relationships between the canthal parameters and other maxillofacial parameters like anterior maxillary teeth (Al Wazzan, 2001) and maxillary central incisor width (Abdullah, 2002) should be carried out. This will add to the knowledge of maxillofacial relationships, which is important for efficient correction of maxillofacial and craniofacial disorders.

\section{REFERENCES}

Abdullah A. 2002. Inner canthal distance and geometric progression as a predictor of 
maxillary central incisor width. $J$. Prosthetic Dent., 88(1): 16-20.

Al Wazzan KA. 2001. The relationship between intercanthal dimension and the widths of maxillary anterior teeth. J Prosthetic Dent., 86(6): 608-612.

Bruce NE, Timothy AT. 1992. The surgical correction of craniofacial synostosis and craniosynostosis deformities. In Principles of Oral and Maxillofacial Surgery, Peterson LJ et al. (eds). Lippincott Company 3; 1489-1530.

Evereklioglu C, Dogonay S, Er H, Gunduz A, Tercan M, Balat A, Cumursu T. 2002. Craniofacial anthropometry in a Turkish population. Cleft Palate Craniofacial J., 39(2): 208-218.

Everekliogu C, Yakinci C, Er H, Dogonay S, Durmaz Y. 2000. Normative values of caniofacial measurements in idiopathic Benign Macrocephalic children. Cleft Palate Craniofacial J., 38(3): 260-263.

Freihofer HP. 1980. Inner intercanthal and interorbital distances. J. Maxillofacial Surg., 8(4): 324-326.

Gupta VP, Sodhi PK, Pandey RM. 2003. Normal values for inner intercanthal, interpupillary and outer intercanthal distances in the Indian population. Int. J. Clin. Pract., 57(1): 25-29.

Murphy WK, Laskin DM. 1990. Intercanthal and interpupillary distances in the black population. Oral Surg. Oral Med. Oral Pathol., 69(6): 676-680.

Ngeow WC, Akan A. 2005. The intercanthal and interpupillary distance in an Asian population. Convention on Craniofacial growth and development (Human) in Baltimore Centre Exhibit Hall E-F, Friday 11 March, 2005.

Quant JR, Woo GC. 1992. Normal values of eye position in the Chinese population of Hong Kong. Optom. Vis. Sci., 69(2): 152158.

Williams PC, Bannister LH, Berry NM, Collins P, Dyson M, Dussek HE, Fergusson MNJ. 1995. Gray's Anatomy $\left(38^{\text {th }}\right.$ edn $)$ Edinburgh Churchill Livingstone.

Zhang M, Hong R, Fu Z, Ye M, Yang $\mathrm{H}$. 2000. The measurement of normal values of exophthalmos, interpupillary distance and interorbital distance of children and adolescence in Xiamen and the rule of their development. Zhonghua Yan ke Za Zhi., 36(6): 462-466. 